\title{
Repair Adhesive Strength of Conventional and Bulk Fill Resins Using Different Bonding Techniques
}

\section{Resistência Adesiva de Reparo em Resinas Compostas Convencionais e 'Bulk-Fill' Utilizando Diferentes Técnicas de Adesão}

\author{
Wilian Segatto Zanelli*a; Mariana Dias Flor-Ribeiro ${ }^{\mathrm{a}}$; Rodrigo Barros Esteves ${ }^{\mathrm{a}}$; Luís Roberto Marcondes Martins ${ }^{\mathrm{a}}$; \\ Flávio Henrique Baggio Aguiar ; Giselle Maria Marchia
}

aUniversidade Estadual de Campinas, School of Dentistry of Piracicaba, Department of Restorative Dentistry. SP, Brazil.

*E-mail address: wilian.segatto@gmail.com.br

\begin{abstract}
This research aimed to evaluate the bond strength by micro tensile strength ( $\mu$ TBS), elastic modulus (EM) and flexural strength (FS) by the three-point test using three types of composite resins: Charisma Diamond, Filtek Z350 and Tetric N-Ceram Bulk Fill; and three adhesion techniques: adhesive, silane, silane and adhesive. The combinations of each resin with the adhesive technique resulted in nine groups $(\mathrm{n}=12)$. Initially, with the composites, EM and FS tests were performed. Sequentially, each fragment was repaired with the different adhesive systems. All samples were subjected to $\mu$ TBS testing on a universal assay machine. Data were subjected to the normality test and the parametric ANOVA test. Charisma resin showed the highest values in EM and RF compared to the other composite resins $(\mathrm{p}<0.05)$. The highest $\mu$ TBS value was for silane + adhesive repaired Charisma resin. The lowest $\mu$ TBS values were in Bulk Fill resin, regardless of adhesive system. The EM and FS results showed that Filtek Z350 resins had the best results, while bulk fill resins had lower results. It was concluded that Charisma and Filtek Z350 resins presented better results. However, in the bulk fill group, the lowest mean values of $\mu$ TBS, FS and EM were obtained, as well as the lowest value in EM.
\end{abstract}

Keywords: Composite Resins. Adhesives. Flexural Strength.

\section{Resumo}

Esta pesquisa teve como objetivo avaliar a resistência de união (RU) por resistência à microtração, módulo de elasticidade (ME) e resistência à flexão $(R F)$ pelo teste de três pontos, utilizando três tipos de resinas compostas: Charisma Diamond, Filtek Z350 e Tetric N-Ceram Bulk Fill; e três técnicas de adesão: adesivo, silano, silano e adesivo. As combinações de cada resina com a técnica adesiva resultaram nove grupos (n =12). Inicialmente, com os compósitos foram realizados testes de ME e RF. Sequencialmente, cada fragmento foi reparado com os diferentes sistemas adesivos. Todas as amostras foram submetidas ao teste de RU por microtração em uma máquina de ensaio universal. Os dados foram submetidos ao teste de normalidade e ao teste paramétrico ANOVA. A resina Charisma apresentou os maiores valores no ME e RF em relação às demais resinas compostas $(p<0,05)$. O maior valor de $R U$ foi para a resina Charisma reparada com silano + adesivo. Os menores valores de RU foram na resina Bulk Fill, independentemente do sistema adesivo. Os resultados no ME e RF mostraram que as resinas Filtek Z350 obtiveram os melhores resultados, enquanto as resinas bulk fill obtiveram resultados inferiores. Conclui-se que as resinas Charisma e Filtek $Z 350$ apresentaram melhores resultados. Entretanto, no grupo de bulk fill obteve-se as menores médias de RU, RF e ME, bem como o menor valor no ME.

Palavras-chave: Resinas Compostas. Adesivos. Resistência à Flexão.

\section{Introduction}

Composite resin is considered to be the most excellent restorative material and the most sought after in the dental clinic, in place of amalgam, presenting high clinical predictability, in addition to longevity ${ }^{1,2}$. This fact is due to the concern related to a minimally invasive dentistry, evidencing the success of the adhesive technique currently, in addition to returning a satisfactory esthetic to the patient, in view of the patients' increasing demand ${ }^{1}$.

With the advancement of research on composite resins, the new generation of composite resin, bulk fill, has demonstrated better mechanical properties, even though it is used in larger quantities in increments, making it usually used in subsequent restorations ${ }^{3}$. With the possibility of using larger quantities in increments $(4 \mathrm{~mm})$, the procedures have become more agile and simple, and even so, there are no harmful effects on polymerization contraction, cavity adaptation or conversion degree $^{4}$. A study conducted by Mothy et al. ${ }^{5}$ compared conventional composite resin with two types of bulb fill composite resins, namely SDR (DENTSPLY Caulk) and X-tra base (VOCO GmbH, Cuxhaven, Germany), and obtained that the groups of bulk fill composite resins obtained significantly lower deflection values in cusps, in relation to conventional composite resins, while there was no difference in cervical micro infiltration among the types of resins.

Much has already been demonstrated about the success of composite resin-based composites, with the advantages of the dentin-like modulus of elasticity, flexural strength, that 
is, less deformation of the composite resin when submitted to the different types of stresses ${ }^{6}$, which is clinically observed in chewing ${ }^{7}$; less invasive cavitary preparations ${ }^{8}$. However, such composites still present disadvantages, such as marginal infiltration and bonding failures between substrate and composite ${ }^{9,10}$. Besides these, secondary fractures and caries give a limited longevity to the restorations of composite resins ${ }^{10}$; and, normally, when such failures occur, restorations are completely removed, generating a significant loss of dental structure ${ }^{1,11}$.

Thus, aiming at dental preservation and based on minimally invasive Dentistry, repair is indicated as an alternative to substitution, since besides being simple to manufacture, it increases the clinical longevity of restorations and reduces the occurrence of potentially harmful effects on dental pulp, ${ }^{12}$ being positive for both the professional and the patient. In addition, composite resin repairs can have an effect on reduced costs and clinical time $\mathrm{e}^{10,11,13}$.

The decrease in the risk of caries in many countries makes the indication of repair in restorations an increasingly interesting procedure ${ }^{14}$. However, in the scientific environment there are still doubts related to the integrity and longevity of the restorations in which they were submitted to the repair procedure $^{15}$. Therefore, a repair with high adhesive strength between the existing composite and the new one is essential for the repair process to be successful in restorations ${ }^{16}$.

This need is due to the fact that the restoration of composite resin that is repairable has a surface formed by an organic matrix already curing process, that is, less reactive ${ }^{17}$. Furthermore, it is known that the performance of the repair bond between newly prepared composite resin and already cured resin composite is obtained from three factors, namely: 1) chemical interaction between non-reactive remaining monomer and newly treated composite; 2) micromechanical binding through the monomer infiltration into the newly treated composite and 3) chemical connection to exposed loads on treated composite surfaces ${ }^{18}$.

Sau et al. ${ }^{19}$ also demonstrated that the quantity of nonreactive monomers remaining from composite resins would be influenced by the curing process time. Therefore, resins composed with shorter curing process time would offer advantages in the higher immediate binding force in repair, compared to resins with higher curing process times ${ }^{20}$.

During clinical care, students and dentists in universities face the doubt whether a poor restoration is suitable for replacement or repair. For this reason, criteria were developed and approved by the Science Committee of the FDI World Dental Federation in 2008 and updated in 2010 12. These criteria can be applied to patients during clinical care during the assessment of the restoration and technique used. In addition, such criteria serve as a basis on the subject, as well as improving the student's clinical glance while restorative treatment is decided regarding maintenance, replacement or repair of the restoration ${ }^{12}$.

Thus, the objective of this study was to evaluate the modulus of elasticity and flexural strength of different types of composite resins (Charisma Diamond, HeraeusKulzer, Germany; Filtek Z350, 3M ESPE,St Paul, EUA e Tetric N-Ceram Bulk Fill, IvoclarVivadent, AG, Schaan, Liechtenstein), and the bonding strength of these resins made up of different adhesion techniques (Scotchbond adhesive, 3M ESPE, St Paul, EUA; silano Ceramic Primer RelyX, 3M ESPE, St Paul, EUA; silano Ceramic Primer RelyX, 3M ESPE, St Paul, EUA + Scotchbond adhesive, 3M ESPE, St Paul, EUA). As a null hypothesis we have: there is no difference between the values of mechanical and the bonding strength of the different resins, regardless of the adhesive protocol adopted.

\section{Material and Methods}

\subsection{Experimental design}

Regarding the experimental units, composite resin specimens $(n=12)$ were performed, with approach of adhesion in 3 levels, namely adhesive; silane and silane adhesive, and resin material was used in 3 levels, namely composite nanohybrid resin; nanoparticulate and bulk-fill. The response variable was measured in: response variable; tensile strength $(\mathrm{MPa})$; three-point flexural strength $(\mathrm{MPa})$ and elasticity modulus $(\mathrm{N})$.

The materials used are detailed in Table 1.

Table 1 - Trademark, composition and manufacturers of the materials to be used

\begin{tabular}{|l|l|l|}
\hline \multicolumn{1}{|c|}{ Trademark } & \multicolumn{1}{|c|}{ Composition } & \multicolumn{1}{|c|}{ Manufacturer } \\
\hline $\begin{array}{l}\text { Composite resin } \\
\text { Charisma Diamond }\end{array}$ & $\begin{array}{l}\text { TCD-DI-HEA, UDMA. Nanoparticles: fluorinated aluminum barium glass, Silicon } \\
\text { dioxide }\end{array}$ & $\begin{array}{l}\text { Heraeus } \\
\text { Hanau, Germany }\end{array}$ \\
\hline $\begin{array}{l}\text { Composite resin Filtek } \\
\text { Z350 }\end{array}$ & $\begin{array}{l}\text { UDMA, Bis-GMA, Bis-EMA, TEGDMA. Nanoparticles: non-clustered / non- } \\
\text { clustered silica and zirconia/silica nano-clustered, freely bound clusters consisting } \\
\text { of clusters of primary particles of zirconia/silica. }\end{array}$ & $\begin{array}{l}\text { 3M ESPE,St USA Paul, } \\
\text { MN, USA }\end{array}$ \\
\hline $\begin{array}{l}\text { Composite resin Tetric } \\
\text { N-Cam Bulk Fill }\end{array}$ & $\begin{array}{l}\text { Bis-GMA, Bis-EMA, UDMA. Nanoparticles: barium glass, ytterbium trifluoride, } \\
\text { mixed oxides and copolymers, particles. }\end{array}$ & $\begin{array}{l}\text { IvoclarVivadent, AG, } \\
\text { Schaan, Liechtenstein }\end{array}$ \\
\hline Scotchbond adhesive & BIS-GMA, HEMA solution and photo initiator & $\begin{array}{l}\text { 3M ESPE, St Paul, } \\
\text { MN, USA }\end{array}$ \\
\hline $\begin{array}{l}\text { SilanoCeramic Primer } \\
\text { RelyX }\end{array}$ & Isopropyl alcohol, water, ether & $\begin{array}{l}\text { 3M ESPE, St Paul, } \\
\text { MN, USA }\end{array}$ \\
\hline $\begin{array}{l}\text { Phosphoric acid Ultra- } \\
\text { etch }\end{array}$ & Phosphoric acid, 35\%, thickener & $\begin{array}{l}\text { Ultra-etch, Ultradent, } \\
\text { South Jordan, UT, } \\
\text { USA }\end{array}$ \\
\hline
\end{tabular}

Source: Research data. 
A condensation silicon mold (Zetaplus, Zhermack USA) was used to prepare the samples, obtained from a Teflon matrix with dimensions of $7 \times 2 \times 1 \mathrm{~mm}$, where it was filled with the resinous material, according to ISO 178:2010, except for dimension.

After insertion of composite resins, a $1 \mathrm{~mm}$ thick glass plate was positioned on the top of the impression and the high intensity light-curing tip (VALO, Ultradent Products Inc., South Jordan, UT, USA) was positioned on top of the impression. The light-curing process was performed according to the indication being 20 seconds for Charisma and 40 seconds for Z350, for each type of composite resin.

36 samples were made for each type of resin, all of which were used after 24 hours for the above tests. The samples were taken to a universal assay machine (Instron 4411, Instron LTD, High Wycombe, Buckindamshire, UK) for the performance of the elasticity modulus and flexural strength test by means of a three-point flexural test and, simultaneously, inducing fracture for subsequent tests.

The three-point flexural test followed ISO 6872/1999, which has a basic apparatus attached to the lower clamp of the universal test machine, composed of two parallel-mounted circular cross-section supports of $2 \mathrm{~mm}$ diameter, with $20 \mathrm{~mm}$ distance between the centers. Another device, attached to the top of the machine, measuring $2 \mathrm{~mm}$ in diameter in the circular section, was intended to apply a force in the central region of the sample, previously positioned over the lower jaws.

After the samples fracture, the restorative procedure was performed with the same composite resins used, following the different types of adhesive approach.

Regarding randomization and division of experimental groups, composite resins were divided into nine different groups $(n=12)$, according to the adhesive approach (Chart 2), with the nine groups for immediate evaluation.

Table 2 - Description of experimental groups

\begin{tabular}{|l|c|}
\hline \multicolumn{1}{|c|}{ Composite Resin } & Adhesion Approach \\
\hline \multirow{4}{*}{ Charisma Diamond } & Adhesive \\
\cline { 2 - 2 } & Silane \\
\cline { 2 - 2 } Filtek Z350 & Silane + Adhesive \\
\cline { 2 - 2 } & Adhesive \\
\cline { 2 - 2 } Tetric N-Ceram Bulk Fill & Silane + Adhesive \\
\cline { 2 - 2 } & Adhesive \\
\cline { 2 - 2 } & Silane + Adhesive \\
\hline
\end{tabular}

Source: Research data.

In the restorative procedure, a sample fragment submitted to flexion fracture was restored with its respective type of composite resin, originating a new sample with the same recommended dimensions. These are identical (same type of composite resin and same adhesive approach), which were used for the tensile strength test.

\subsubsection{Adhesive}

For the groups that only application of adhesive as an adhesive system, the adhesive Scotchbond (3M ESPE, St Paul, MN, USA) was used. It started by conditioning the composite resin fractured with phosphoric acid 35\% (UltraEcht - Ultradent, South Jordan, UT, USA) for 30 seconds, washed with water also for 30 seconds, according to the manufacturer's recommendations, and dried with hydrophilic cotton pellets, before the restorative procedure. After this step, the adhesive was applied with the aid of the disposable brush (MicroBrush, KG), with light friction movements, for 15 seconds, dried with light air jet for 5 seconds and finally was light cured for 10 seconds by A VALO curing unit (Ultradent Products Inc., South Jordan, UT, USA).

\subsubsection{Silane}

For the application of silane, the composite was previously conditioned, in the same way as mentioned for the application of the adhesive, followed by its application for 60 seconds with disposable brush (MicroBrush, KG).

\subsubsection{Silane+Adhesive}

For this adhesive approach, the steps of the two techniques mentioned above were associated. Initially, the composite was conditioned with phosphoric acid (Ultra-Echt - Ultradenta $35 \%$ for 30 seconds, washed at the same time with water, and dried with hydrophilic cotton balls. Following the application of silane for 60 seconds and, after its total volatilization, the adhesive Scotchbond (3M ESPE, St Paul, MN, USA) was applied with light friction movements for 15 seconds, volatized for 5 seconds with jets of air and light cured for 10 seconds with VALO light-curing unit (Ultradent Products Inc., South Jordan, UT, USA).

After the restorative procedure, the samples went through the manual sanding finishing procedure in order to eliminate excess adhesive/silane and resin that overflowed the impression.

For the tensile strength test, the samples were positioned and their ends glued with a cyanoacrylate-based adhesive (SuperBonder Gel, Loctite, Henkel, São Paulo, SP, Brazil) in appropriate metal devices of the universal assay machine (EZ Test L, Shimadzu, Japan) with a load cell of $500 \mathrm{kgf}$ at a speed of $0.5 \mathrm{~mm} / \mathrm{min}$ until generating the sample fracture. After fracture, the sectioned area was measured with digital pachymeter (Mitutoyo Corporation, Tokyo, Japan) and the strength calculated in MPa.

The values obtained were calculated to quantify the rupture modulus of each sample $(\sigma)$ (equation 1$)$ : 


$$
\sigma=3 F \mathbf{~} / 2 b^{2}
$$

where:

$\mathrm{F}=$ maximum force $(\mathrm{N})$

$1=$ distance between bearings $(\mathrm{mm})$

$\mathrm{b}=$ sample width $(\mathrm{mm})$

$\mathrm{b}=$ sample thickness $(\mathrm{mm})$

\subsection{Statistical Analysis}

The data obtained were evaluated by normality test (Kolmogov Smirnov and Shapiro - Wilk), where $\mathrm{p} \geq 0.05$ was considered normal. After the normality test, ANOVA one factor parametric test was applied, with Tukey post-hoc test, demonstrating that the data obtained have $\mathrm{p} \leq 0.05$, that is, they have statistical significance.

\section{Results and Discussion}

Fractured composite resin restorations that have an indication of repair require an adequate adhesion force to the bonding interface, either to the fractured restorative material and/or dental substrate, in order to favor greater durability. In the scientific literature, there is still no consensus related to the appropriate protocol for the treatment of the surface of fractured composite resin restorations during the repair procedure $^{21}$.

In Table 3 , the results on modulus of elasticity and flexural strength were obtained. Thus, it was noted that the Charisma and Filtek Z350 groups had the best results in both the elasticity and flexural strength modulus, while the bulk fill group presented the lowest values statistically.

Table 3 - Results of elasticity (GPa) and flexural strength (MPa) modulus

\begin{tabular}{|c|c|c|}
\hline Groups & $\begin{array}{c}\text { Elasticity } \\
\text { modulus }\end{array}$ & $\begin{array}{c}\text { Flexural } \\
\text { Strength }\end{array}$ \\
\hline Charisma & $5.75 \pm 0.92 \mathrm{~A}$ & $151.1 \pm 27.76 \mathrm{~A}$ \\
\hline Filtek Z350 & $4.09 \pm 0.63 \mathrm{~B}$ & $110.27 \pm 17.49 \mathrm{~B}$ \\
\hline Bulk fill & $4.85 \pm 0.71 \mathrm{~B}$ & $100.73 \pm 18.03 \mathrm{~B}$ \\
\hline
\end{tabular}

Means followed by equal letters are not statistically significant $(\mathrm{p}>0.05)$. $\mathrm{n}=12$ samples / group.

Source: Research data.

Regarding the results of bonding strength, it was possible to observe in table 4 that the highest bonding strength was perceived for Charisma resin repaired with silane adhesive ( $<<0.44$ ), being statistically similar to Charisma repaired only with adhesive and Filtek Z350 repaired with silane only. On the other hand, the lowest values of adhesive strength were observed in the Tetrik N-Cam Bulk Fill resin regardless of the adhesive system used.
Table 4 - Mean and standard deviation of bonding strength (MPa)

\begin{tabular}{|l|l|}
\hline \multicolumn{1}{|c|}{ Group } & \multicolumn{1}{c|}{ MPa } \\
\hline Charisma + Adhesive & $28.13 \pm 4.63 \mathrm{AB}$ \\
\hline Charisma + Silane & $23.61 \pm 6.30 \mathrm{~B}$ \\
\hline Charisma + Adhesive and Silane & $30.90 \pm 5.23 \mathrm{~A}$ \\
\hline Filtek Z350 + Adhesive & $19.86 \pm 9.41 \mathrm{BC}$ \\
\hline Filtek Z350 + Silane & $27.38 \pm 3.85 \mathrm{AB}$ \\
\hline Filtek Z350 + Adhesive and Silane & $18.48 \pm 5.63 \mathrm{BC}$ \\
\hline Bulk fill + Adhesive & $18.93 \pm 4.65 \mathrm{BC}$ \\
\hline Bulk fill + Silane & $21.04 \pm 3.96 \mathrm{~B}$ \\
\hline Bulk fill + Adhesive and Silane & $17.23 \pm 3.96 \mathrm{BC}$ \\
\hline
\end{tabular}

Means followed by equal letters are not statistically significant $(\mathrm{p}>0.05)$. $\mathrm{n}=12$ samples / group.

Source: Research data.

Thus, based on our study, the compound resin Charisma presented a better performance related to the bonding strength of fractured restorations submitted to repair by the adhesive technique with adhesive and silane, differently from the other resins composed, therefore, the hypothesis of our study was rejected.

The repair technique is currently being well accepted in clinical procedures, since in addition to requiring less clinical time, there is a lower risk of unnecessary substrate wear, compared to the replacement technique of a restoration ${ }^{22}$. Therefore, there is an extreme need for research that provides a comparison of the effects of different protocols on repair.

Regarding the elasticity and flexural strength modulus, the compound resin Charisma obtained a better result and one of the reasons may be related to the size of its inorganic particles. According to the scientific literature, there is a greater strength of the composite resin when inorganic particles are smaller (200 to $70 \mu \mathrm{m})^{23}$, correlated with our study, considering that the compound Charisma resin has smaller inorganic particles, compared to the particles found in the Filtek Z350 and bulk fill resins. Authors Zhao et al. ${ }^{24}$ on the other hand, tell us that larger particles provide the composite resin with higher conversion levels and dynamic and static elasticity modulus.

As we have seen in our study, all the groups of composite resins that used only the adhesive as an adhesive system obtained satisfactory values in the bonding strength and a hypothesis about this result may be related to the adhesive action mechanism, chemical interaction with the remaining monomers not reacted in previously light-cured composites; micromechanical binding by infiltration of monomers into the polymerized composite; and chemical binding to exposed loads of the surface of the light-cured composite ${ }^{18}$.

In addition, polymerization time influences the amount of non-reactive resinous monomers remaining from polymerized composites $^{19}$. Therefore, composite resins that have a shorter polymerization time tend to have a better performance in adhesion of immediate repairs ${ }^{20}$. According to Table 4, the Charisma resin group requiring 20 seconds of polymerization obtained a better result of elasticity module $(5,75 \mathrm{GPa})$ and flexural strength $(151 \mathrm{MPa})$, while the Filtek Z350 and bulk fill groups requiring 40 seconds of polymerization, there were 
no statistical differences in such tests and this may justify the best mechanical behavior of Charisma resin compared to the others.

In addition to these, another important factor for the performance of adhesion of the newly inserted resin is the existence of a double bond between unreacted carbons in polymerized resin ${ }^{25}$. This quantity of unreacted monomers of polymerized resins depends directly on the chemical composition of the resin matrix and its polymerization behavior ${ }^{20}$. In other words, the greatest strength of adhesion among newly repaired composite-composite occurs as a result of the highest quantity of unreacted monomers, derived from polymerized resin ${ }^{26}$.

However, even though there are all these factors and mechanisms that play a favorable role for a good adhesion force of the adhesive in the repair, it must be well disposed, both in the already polymerized resin, as for the newly inserted composite and one of the factors that facilitates good flow is the low adhesive viscosity. Kanzow et al. ${ }^{27}$, show that the lowest viscosity of the Scotchbond universal adhesive provides a better flow into the substrate and with this, greater adhesion strength, when compared to higher viscosity adhesives. In addition, the author says that the incorporation of a silane bonding agent to the Scotchbond adhesive further improves the bonding and shear strength in aged composites, since they form bonds to the exposed load particles. This information is consistent with the results of the bonding strength of our groups in which both adhesive and silane adhesive were applied.

Another research that is favorable to the use of the adhesive system with the silane bonding agent is by Altinci et al. ${ }^{21}$, where their research says that the treatment with silane in repair procedures has, as a function, to promote the chemical binding, forming siloxane connections among the load particles containing silicate, exposed on the repair surface near the matrix of the newly repaired resin. It is also known that silane increases surface wettability, obtaining a favorable micromechanical connection in the repair interface ${ }^{28}$. Similar to the literature above, we obtained favorable bonding strength values when using a compound adhesive system with silane.

However, so that the adhesion force of a repair to be clinically accepted, it is necessary to obtain bonding strength values of at least $18 \mathrm{MPa}$ or values between 20-25 $\mathrm{MPa}^{29}$. In our study, with the exception of bulk fill resin, the other resins evaluated with different protocols of adhesive systems obtained clinically accepted values for repair procedures.

On Filtek Z350 resin, a lower performance in the bonding strength was obtained in our study, when compared to micro hybrid resin and a hypothesis are the clusters of primary particles present in Z350 resin, because they are clusters of nanometric silica and non-silanized zirconia particles weakly bound to the resin matrix ${ }^{30}$. This allows these load particles to be exposed on the prepared resin surface.
To avoid this, Alqarni et al. ${ }^{20}$, applied a silane coupling binding agent to the exposed load particles of the adhesive, seeking to increase the resin micro traction strength. However, this application of silane coupling agent did not help in a better performance in the micro traction strength in all the tested resin composites.

The above study is consistent with our result, since we obtained that the composite resin Z350 had a lower performance in the bonding strength, so much so that there was no statistical difference $(\mathrm{p}<0.5)$ with the composite resin group bulk fill, which had the worst performance in the bonding strength in all the adhesive system protocols. Suggesting that such resins require, for example, a higher surface roughness, obtained by the use of phosphoric acid at $10 \%$, because Ayar MK et al. ${ }^{31}$ only obtained repair strength values efficient between bulk fill resin with conventional composite resin, and vice versa, when $10 \%$ phosphoric acid plus resin adhesive system was used.

Even with low values of the bulk fill resin, both of flexural strength and of binding strength, the scientific literature shows that the bulk fill provides satisfactory adhesion resistance, regardless of the increment technique of the composite and the cavity depth ${ }^{32}$. However, our study contradicted such data, since the composite resin bulk fill obtained lower values of bonding resistance, regardless of the adhesive system used ( $p$ $<0.5)$.

In general, with what was exposed, we believe that bulk fill resin is not contraindicated for repair procedures, however we emphasize that it is possible to use other surface preparation protocols ${ }^{31}$. On the other hand, Charisma composite resin presented the best performance to be used in repair procedures, since it presented better results of binding strength in the different protocols of adhesive systems.

\section{Conclusion}

The present study demonstrated that the groups of Charisma composite resins presented the best results on the elasticity and flexural strength modulus, besides the best results in the bonding strength using the adhesive technique associating silane with the adhesive.

The bonding strength was not influenced by the adopted adhesive technique, but the restorative material was significant.

\section{References}

1. Sharif MO, Catleugh M, Merry A, Tickle M, Dunne SM, Brunton P. et al. Replacement versus repair of defective restorations in adults: resin composite. Cochrane Database Syst Rev 20148;(2):CD005971. doi:10.1002/14651858. CD005971.

2. Ástvaldsdóttir Á, Dagerhamn J, van Dijken JW, NaimiAkbar A, Sandborgh-Englund G, Tranæus S et al. Longevity of posterior resin composite restorations in adults: a systematic review. J Dent 2015;43(8):934-54. doi: 10.1016/j. jdent.2015.05.001.

3. Ikeda I, Otsuki M, Sadr A, Nomura T, Kishikawa R, Tagami 
J. Effect of filler content of flowable composites on resincavity interface. Dent Mater J 2009;28(6):679-85.

4. Czasch P, Ilie N. In vitro comparison of mechanical properties and degree of cure of bulk fill composites. Clin Oral Investig 2013;17(1):227-35. doi: 10.1007/s00784-012-0702-8.

5. Moorthy A, Hogg $\mathrm{CH}$, Dowling AH, Grufferty BF, Benetti AR, Fleming GJ. Cuspal deflection and microleakage in premolar teeth restored with bulk-fill flowable resin-based composite base materials. J Dent 2012;40(6):500-5. doi: 10.1016/j.jdent.2012.02.015.

6. Sabbagh J, Vreven J, Leloup G. Dynamic and static moduli of elasticity of resin-based materials. Dent Mater 2002;18(1):6471.

7. Fares NH., et al. Flexural strength and static modular elasticy of composite resin. RevClínica Pesquisa Odontol 2005;2(1):53-7.

8. Manhart J, Chen H, Hamm G, Hickel R. Buonocore Memorial lecture. Review of the clinical survival of direct and indirect restorations in posterior teeth of the permanent dentition. Oper Dent 2004;29(5):481-508.

9. Da Silveira RR, Silva MES, Souza EL, Giovannini JFBG, Francisconi PAS. Avaliação da resistência de união de reparos de resina composta, utilizando-se diferentes tratamentos de superfície. Arq Odontol 2012;48(4):234-41.

10. Ribeiro MDF, Pazinatto FB. Critérios clínicos para decisão entre substituição ou reparo de restaurações em resina composta: revisão de literatura. Rev Bras Odontol 2016;73(3):223-30.

11. Hickel R, Peschke A, Tyas M, Mjör I, Bayne S, Peters M, et al. FDI World Dental Federation: clinical criteria for the evaluation of direct and indirect restorations-update and clinical examples. Clin Oral Investig 2010;14(4):349-66. doi: 10.1007/s00784-010-0432-8.

12. Masioli MA, Pimentel FL, Louro RL, Masili DLC. Reparo em restaurações de resina composta: procedimento simples e conservador. Rev Bras Pesq Saúde 2006;8(3):38-43.

13. Hickel R, Brüshaver K, Ilie N. Repair of restorations: criteria for decision making and clinical recommendations. Dent Mater 2013;29(1):28-50. doi: 10.1016/j.dental.2012.07.006.

14. Rinastiti M, Özcan M, Siswomihardjo W, Busscher HJ, van der Mei HC. Effect of biofilm on the repair bond strengths of composites. J Dent Res 2010;89(12):1476-81. doi: 10.1177/0022034510381395.

15. Cavalcanti AN, De Lima AF, Peris AR, Mitsui FH, Marchi GM. Effect of surface treatments and bonding agents on the bond strength of repaired composites. J Esthet Restor Dent 2007;19(2):90-8.

16. Maneenut C, Sakoolnamarka R, Tyas MJ. The repair potential of resin composite materials. Dent Mater 2011;27(2):e20-7. doi: 10.1016/j.dental.2010.09.006.

17. Ozcan M, Barbosa SH, Melo RM, Galhano GA, Bottino MA. Effect of surface conditioning methods on the microtensile bond strength of resin composite to composite after aging conditions. Dent Mater 2007;23(10):1276-82.

18. Sau CW, Oh GS, Koh H, Chee CS, Lim CC. Shear bond strength of repaired composite resins using a hybrid composite resin. Oper Dent 1999;24(3):156-61.

19. Alqarni D, Nakajima M, Hosaka K, Ide K, Nagano D, Wada $\mathrm{T}$, et al. The repair bond strength to resin matrix in cured resin composites after water aging. Dent Mater J 2019;38(2):23340. doi: $10.4012 / \mathrm{dmj} .2018-044$.

20. Altinci P, Mutluay M, Tezvergil-Mutluay A. Repair bond strength of nanohybrid composite resins with a universal adhesive. Acta Biomater Odontol Scand 2017;4(1):10-9. doi: 10.1080/23337931.2017.1412262.

21. Wendler M, Belli R, Panzer R, Skibbe D, Petschelt A, Lohbauer U. Repair bond strength of aged resin composite after different surface and bonding treatments. Materials (Basel) 2016;9(7). doi: 10.3390/ma9070547.

22. Shinkai K, Taira Y, Suzuki S, Kawashima S, Suzuki M. Effect of filler size and filler loading on wear of experimental flowable resin composites. J Appl Oral Sci 2018;26:e20160652. doi: 10.1590/1678-7757-2016-0652.

23. Zhao L, Jian YT, Wang XD, Zhao K. Bond strength of primer/cement systems to zirconia subjected to artificial aging. J Prosthet Dent 2016;116(5):790-6. doi: 10.1016/j. prosdent.2016.03.020.

24. Cornelio RB, Wikant A, Mjosund H, Kopperud HM, Haasum J, Gedde UW, Örtengren UT. The influence of bis-EMA vs bis-GMA on the degree of conversion and water susceptibility of experimental composite materials. Acta Odontol Scand 2014;72:440-7. doi: 10.3109 / 00016357.2013 .856467$.

25. Cornelio RB, Wikant A, Mjøsund H, Kopperud HM, Haasum $\mathrm{J}$, Gedde UW, et al. The influence of bis-EMA vs bis GMA on the degree of conversion and water susceptibility of experimental composite materials. Acta Odontol Scand 2014;72(6):440-7. doi: 10.3109/00016357.2013.856467.

26. Kanzow P, Wiegand A, Göstemeyer G, Schwendicke F. Understanding the management and teaching of dental restoration repair: Systematic review and metaanalysis of surveys. J Dent 2018;69:1-21. doi: 10.1016/j. jdent.2017.09.010.

27. Fornazari IA, Wille I, Meda EM, Brum RT, Souza EM. Effect of Surface Treatment, Silane, and Universal Adhesive on Microshear Bond Strength of Nanofilled Composite Repairs. Oper Dent 2017;42(4):367-74. doi:10.2341/16-259-L.

28. Kupiec KA, Barkmeier WW. Laboratory evaluation of surface treatments for composite repair. Oper Dent 1996;21(2):59-62.

29. Curtis AR, Shortall AC, Marquis PM, PalinWM. Water uptake and strength characteristics of a nanofilled resinbased composite. J Dent 2008;36:186-93. doi: 10.1016/j. jdent.2007.11.015.

30. Ayar MK, Guven ME, Burduroglu HD, Erdemir F. Repair of aged bulk-fill composite with posterior composite: Effect of different surface treatments. J Esthet Restor Dent 2019;31(3):246-52. doi: 10.1111/jerd.12391.

31. Van Ende A, De Munck J, Van Landuyt KL, Poitevin A, Peumans M, Van Meerbeek B. Bulk-filling of high C-factor posterior cavities: effect on adhesion to cavity-bottom dentin. Dent Mater 2013;29(3):269-77. doi: 10.1016/j. dental.2012.11.002. 